\title{
Present Prospectus of Malnutrition in Bangladesh: A Comprehensive Review
}

\author{
Md. Reyad-ul-Ferdous ${ }^{1,2,3,4, a^{*}}$, Mohammad Atiqur Rahman ${ }^{5, b}$, \\ Al Imran Ahmed ${ }^{6, c}$, Mehedi Rahman ${ }^{2, d}$, Antara Mehzebeen Zaman ${ }^{2, e}$ \\ ${ }^{1}$ Department of Pharmacy, Progati Medical Institute, Dhaka-1216, Bangladesh. \\ ${ }^{2}$ Department of Pharmaceutical sciences, North South University, Dhaka-1229, Bangladesh. \\ ${ }^{3}$ Department of Pharmacy, State University of Bangladesh, Dhaka-1207, Bangladesh. \\ ${ }^{4}$ Institute for Nutritional Sciences, Shanghai Institutes for Biological Sciences, \\ Chinese Academy of Sciences, Shanghai, China. \\ ${ }^{5}$ Department of Pharmacy, Stamford University, Dhaka-1209, Bangladesh. \\ ${ }^{6}$ Department of Pharmacy, University of Asia Pacific, Dhaka-1215, Bangladesh. \\ *Corresponding author: Md. Reyad-ul-Ferdous (Ph.D), Lecturer, Department of Pharmacy, \\ Progati Medical Institute, Dhaka-1216, Bangladesh. \\ Email Address: ${ }^{a}$ rockyreyad@yahoo.com, ${ }^{\mathrm{b}}$ rahman.atiq90@gmail.com, \\ calimranahmed29@gmail.com, 'rmehedi11@gmail.com, eantara.m.zaman@gmail.com .
}

Keywords: Dietary pattern of Bangladeshi people, Malnutrition problem, Nutrition-relevant programs, Nutrition \& education, Vitamin A, D deficiency in Bangladesh.

Abstract. Malnutrition is both over nutrition and under nutrition. As in Bangladesh the rapidity of under nutrition is too elevated, although slow, the rate of overweight and obesity in children and women is also rising. Under-nutrition results from micronutrient including essential vitamins and minerals deficiencies and both macro (protein energy deficiency). Malnutrition is anticipated to be causes of about $60 \%$ of maternal childhood and deaths in Bangladesh. Development in overall nutritional condition has been sluggish over the years. Rate of feasting and underweight both remain inappropriately very high in the country still.

\section{Introduction}

As we see that Bangladesh has recorded remarkable poverty lessening over the last few decades but still more than two-thirds of mothers do not eat satisfactorily diverse food. Low birth weight $(<2500 \mathrm{~g})$ also directs to childhood under nutrition $[1,2]$. Bangladesh has the highest number of low birth weight rate in the world because one in five children is born with low birth weight $[3,4]$.

Nevertheless, developments in the nutritional position of Bangladeshi domestics have been monotonous. According to the Bangladesh Demographic and Health Survey, noticeable among children refused modestly, going from $43 \%$ in 2007 to $41 \%$ percent in 2011 (NIPORT et al. 2012) $[5,6]$.

A nationally delegating survey (State of Food Security and Nutrition in Bangladesh, 2011) anticipated that nearly $45 \%$ of households in Bangladesh undergo from some form of foodstuff insecurity. This study highlighted that the prevalence of insufficient maternal dietary variety is nearly $62 \%$ but that of unceasing malnutrition among children is $45 \%$ [7]. This is interconnected to socio-economic class and to the age of preface of balancing food. Bangladesh has attained a quite high coverage of vitamin A supplementation in under-5 children and has been thriving in get rid of night blindness $[8,9]$. 


\section{Objectives}

The overall objective of the review was to describe the pervasiveness of malnutrition and also categorize the associated determinants in Bangladesh and also the prevalence of chronic energy scarcity and anemia and other vitamin deficiency and to illustrate the basic determinants of malnutrition.

\section{Dietary pattern of Bangladeshi people}

The typical diet Bangladeshi people is greatly dependent on rice and puffed rice remain the major source of energy in their diet. Food consumption prototypes in Bangladesh illustrate very modest diversity even at the national stage. The price rate of non-rice foods that are rich in nutrients also demonstrate a rising trend and the poor are additional price-responsive than the rich [10, 11]. The squat micronutrient content of the diet fundamentally explains the high pervasiveness of micronutrient scarcity in Bangladesh [12].

\section{Vitamin A deficiency in Bangladesh}

Dominance of subclinical VAD in teenager remained relatively lesser than other population factions in Bangladesh. A study demonstrated about 1.5\% of children (aged between 11-16 years) of Dhaka to suffer from subclinical VAD (serum retinol $<0.70 \mu \mathrm{mol} / \mathrm{L}$ ). Another study accounted that $51 \%$ pregnant women had shortage in diets for vitamin A, and $18.5 \%$ marked VAD (serum retinol $<0.70 \mu \mathrm{mol} / \mathrm{L}$ ), suggesting VAD to be extremely prevalent among pregnant women in countryside Bangladesh. (See table 1) VAD has been more critically addressed in Bangladesh compared to the neighboring countries like as India, Pakistan, Afghanistan, and Nepal [13]. Several interference programs initiated in the past resulted in noteworthy diminution in night blindness cases among children in Bangladesh. Government precedence to invest in VAD exclusion is the most considerable one among these advances [14].

Table 1: Vitamin A deficiency among male and female in Bangladesh.

\begin{tabular}{|l|l|c|c|}
\hline \multicolumn{1}{|c|}{ Deficiency } & Gender & Age & Percentage \\
\hline Night blindness & Male and female & 6-59 month & 0.67 \\
\hline Bitot's spot & Male and female & 6-59 month & 0.25 \\
\hline Xerophthalmia & Male and female & 6-59 month & 0.1 \\
\hline Corneal xerosis & Male and female & 6-59 month & 0.01 \\
\hline
\end{tabular}

\section{Vitamin D deficiency in Bangladesh}

The function of micronutrients mainly zinc in childhood diarrhoea is sound recognized. Immunomodulatory roles of vitamin-D in diarrhoea and its responsibility in the consequence of additional micronutrients are not sounding implicit [15]. As we know during prenatal third-trimester vitamin D supplementation (875 $\mu \mathrm{g}$ (35 $000 \mathrm{IU}) /$ week) appreciably ameliorated newborn vitamin D condition during the neonatal phase when the jeopardy of vitamin D deficiency is most [16]. Various works projected to find out the class of these micronutrients in local population have accounted that the people in Bangladesh are at soaring risk of hypovitaminosis D related health difficulties [17].

\section{Iron and Iodine nutrition in Bangladesh}

As we know over $70 \%$ of the Bangladeshi population live in rural areas and it is also known on average, $50 \%$ are illiterate, and one-fourth of the population live below the hard core scarcity level (energy intake $<1805 \mathrm{kcal} /$ person/day)) [18]. 22\% are ignorant of iodized salt, and the level of this lack of understanding was high among pregnant women. Such unawareness involves that most of this population is ignorant of other health and nutrition issues as we know iron deficiency is associated with increased risks for mainly of the general diseases like fever, diarrhea/dysentery and pneumonia and skin disease [16]. Iron deficiency amongst pregnant women has been suggested to reason about a predictable 111,000 maternal deaths each year worldwide. Bangladesh launched an Iodine Deficiency Disorder (IDD) management program in 1994 to eliminate iodine deficiency by 2000 but it did not work properly [19]. 


\section{Malnutrition problem in women}

Women are much more likely to suffer from malnutrition than men. Some possible reasons like women's reproductive biology and stumpy social status, poverty and lack of knowledge craft the women more vulnerable to malnutrition. In addition, menstruation and pregnancy and lactation can direct to nutritional deficiency and this is the most extensive and immobilizing health related crisis among women [20]. Micronutrient deficiencies are too connected with pregnancy impediments and maternal mortality [21]. In Bangladesh it is found that almost half of women are suffering from persistent malnutrition. Further being significant causes of disability and micronutrient deficiencies habitually trigger additional types of morbidity. And malnutrition in women leads to financial losses for families and country as malnutrition reduces women's capability to work and can generate worse effects that extend through generations [22].

\section{Nutrition relevant programs}

Accomplishment of unswerving nutrition interferences will be guided by National Nutrition Services (NNS) Operational Plan. NNS has beleaguered the top recommended interferences for accomplishment. Endorsement of elite breastfeeding for 6 months and continued breastfeeding up to 2 years and preface of complementary foods of sufficient nutritional quality following the age of 6 months and salt iodization, growth monitoring and improved hygiene practices and micronutrient supplementation are main. Schedule supplementation of vitamin A supplements is listed with measles vaccination (for $<1$ year children) and armored through "National Vitamin A plus Campaign (NVAC)" since 2003 [23].

\section{Social protection for nutrition}

The government of Bangladesh functions a number of social fortification programmes to ensure food security in the country. Open market sales (OMS), Vulnerable Group Development (VGD) programs, Food for Work (FFW) programs, Vulnerable Group Feeding (VGF) program and employment in char areas are noteworthy. Save the Children as well holds several social protection

programs to be expected to improve food sanctuary of susceptible populations. ${ }^{[10]}$ Correct maintaining of the extraction period and improvement of vigorous surveillance system are extremely recommended for public health safety in dairy farm and collecting fruits and vegetables [24].

\section{Importance of institutional and multi-sectoral collaboration}

Progress of the health region requires direct interaction and involvement and collaboration with policies and programs. Government ministries and agencies and personal and other non-state health service contributors and professional associations and mass media should have to contribute for development of health sector. The possibility of such teamwork will be addressed throughout the next sector program to institutionalize the roles of various actors in mass media. Inside the government, courses of a number of relevant ministries strengthen health outcomes like Ministry of Local Government and Rural Development \& Cooperatives (MOLGRDC). Suppliers and drug producers are also important in the accomplishment of this subdivision program [25].

\section{Nutrition strategy}

World Food Program (WFP) Bangladesh focuses on scaling up nutrition interferences in exceedingly food apprehensive regions with the aim of intensification nutrition security mainly for women and children. Additional $25 \%$ of live births in low- and also in middle-income countries are at full phrase with low birth mass. By providing the right food at the correct time WFP will priorities the condition of equipped food supplements as a medium for micronutrient intake. WFP directly trying support the development of local production of nutritionally-enhanced food supplements to build up a cost effective solutions. The Strategy centre's on humanizing access to healing and preventive nutrition services and intensification of national and home abilities to sufficiently distribute nutrition services and a greater focus on mainstreaming nutrition elements 
into all relevant social safety. The Ministry of Health and Family Welfare of Bangladesh applied strong countermeasures to improve the health state of the nation. However, stand on the perception of the Declaration of Alma-Ata, corresponding and substitute medicine should be used more energetically to improve public health in this country. The practice of corresponding and substitute medicine such as ayurvedic medicine (AM) should be enlarged in Bangladesh [26].

\section{Nutrition education}

Health education; this social promotion can cause alteration of attitude and of the food given to their children amongst mothers. An education and behavior change project should be set up to amplify the superiority of the meals offered during community kitchens. As a result, the ingestion of foods which is rich with vitamin A, iron and vitamin $\mathrm{C}$ will hoist drastically among women and children in the community. In broad, well-designed promotional activities for nutrition education, social advertising and mass media drives will be great successful. Folic acid (FA) supplementation makes easy urinary emission of arsenic. An enhanced appreciative of interactions linking onecarbon metabolism intermediates may pick up the capability to plan nutrition interventions that further make possible arsenic excretion [27].

\section{Conclusion}

Malnutrition is a multifarious social and especially public health crisis; knowledge may help to ease execution of health interventions alongside with other poverty decline activities which are designed to reduce malnutrition. The impacts of agricultural strategies mainly subsidies, the arrangement of production and processing and ultimately on the accessibility of foods basically support healthy food consumption patterns. The key confronts for promoting programmes to foil under nutrition at the national stage in Bangladesh include: insertion nutrition high up on the listing of main concerns, execution of cost-effective and sustainable interferences at scale following suitable strategies, humanizing access to the services for those in genuine require and building up equipped capability.

Conflict of interest: No Conflict of interest.

\section{References}

[1]. S. Akhtar et al., Prevalence of Vitamin A Deficiency in South Asia: Causes, Outcomes, and Possible Remedies, international centre for diarrhoeal disease research, Bangladesh, J. Health Popul. Nutr. 31(4) (2013) 413-423.

[2]. S Jahan et al., Nutritional Profile of Some Tropical Fruits in Bangladesh: Specially AntiOxidant Vitamins and Minerals, Bangladesh Journal of Medical Science. 10(2) (2011) 95-103.

[3]. Information on

http:/www.siteresources.worldbank.org/NUTRITION/Resources/BNGBINP8.pdf.

[4]. Information on http://www.hsmdghs-bd.org/Documents/Doc_APR\%20\%20MTR.pdf.

[5]. Information on http://www.dghs.gov.bd/index.php/en/publications/health-bulletin/dghs-healthbulletin.

[6]. T. Ahmed et al., Nutrition of Children and Women in Bangladesh: Trends and Directions for the Future, J. Health Popul. Nutr. 30(1) (2012) 1-11.

[7]. WFP Bangladesh Nutrition Strategy 2012-2016 (accessed on June 17, 2016). Information on https://www.wfp.org/content/wfp-bangladesh-nutrition-strategy-2012-2016.

[8]. Md. Harun-or-Rashid et al., Iron and iodine deficiencies among under-2 children, adolescent girls, and pregnant women of Bangladesh: association with common diseases, Nagoya J. Med. Sci. 71 (2009) 39-49.

[9]. Information on http://www.unscn.org/layout/modules/resources/files/Policy_paper_No_14.pdf. [10]. Information on http://www.foodfortification.com/files/pdf/WBCSD_case_BASF_final3.pdf. 
[11]. R. Karim et al., Challenges to the Monitoring and Evaluation of Large Nutrition Programs in Developing Countries: Examples from Bangladesh, The Gerald J. and Dorothy R. Friedman School of Nutrition Science and Policy food policy and applied nutrition program, discussion paper no. 1, February 2002. http://econpapers.repec.org/paper/fsnwpaper/01.htm .

[12]. M.R. Chowdhury et al., Risk Factors for Child Malnutrition in Bangladesh: A Multilevel Analysis of a Nationwide Population-Based Survey, J. Pediatr. 172 (2016) 194-201.

[13]. A.S. Faruque et al., Nutrition: basis for healthy children and mothers in Bangladesh, J. Health Popul. Nutr. 26(3) (2008) 325-39.

[14]. S.K. Roy et al., Intensive nutrition education with or without supplementary feeding improves the nutritional status of moderately-malnourished children in Bangladesh, J. Health Popul. Nutr. 23(4) (2005) 320-330.

[15]. A.S. Faruque et al., Nutrition: basis for healthy children and mothers in Bangladesh, J. Health Popul. Nutr. 26 (3) (2008) 325-39.

[16]. M. Rahman, Association between order of birth and chronic malnutrition of children: a study of nationally representative Bangladeshi sample, Cad. Saude Publica. 32(2) (2016) e00011215.

[17]. J.R. Khan, N. Awan, F. Misu, Determinants of anemia among 6-59 months aged children in Bangladesh: evidence from nationally representative data, BMC Pediatr. 16(1) (2016) 3.

[18]. S. Shafique et al., Mineral- and vitamin-enhanced micronutrient powder reduces stunting in full-term low-birth-weight infants receiving nutrition, health, and hygiene education: a $2 \times 2$ factorial, cluster-randomized trial in Bangladesh, Am. J. Clin. Nutr. 103(5) (2016) 1357-1369.

[19]. M.N. Hall et al., Supplementation with Folic Acid, but Not Creatine, Increases Plasma Betaine, Decreases Plasma Dimethylglycine, and Prevents a Decrease in Plasma Choline in Arsenic-Exposed Bangladeshi Adults, J. Nutr. 146(5) (2016) 1062-1067.

[20]. Y. Yoshida et al., Perceptions of Ayurvedic medicine by citizens in Dhaka, Bangladesh, Nagoya J. Med. Sci. 78 (1) (2016) 99-107.

[21]. A.A. Shamim et al., Pregnant Women Diet Quality and Its Sociodemographic Determinants in Southwestern Bangladesh, Food Nutr. Bull. 37(1) (2016) 14-26.

[22]. S. Chowdhury et al., Antibiotic residues in milk and eggs of commercial and local farms at Chittagong, Bangladesh,Vet. World. 8(4) (2015) 467-471.

[23]. H. Sarma et al., Determinants of overweight or obesity among ever-married adult women in Bangladesh, BMC Obes. 1(3) (2016) 13.

[24]. A.M. Ahmed et al., Vitamin-D status is not a confounder of the relationship between zinc and diarrhoea: a study in 6-24-month-old underweight and normal-weight children of urban Bangladesh, Eur. J. Clin. Nutr. 70(5) (2016) 620-628.

[25]. N. Perumal et al., Prenatal vitamin D supplementation and infant vitamin D status in Bangladesh, Public Health Nutr. 6 (2015) 1-9.

[26]. N. Shaheen et al., Presence of heavy metals in fruits and vegetables: Health risk implications in Bangladesh, Chemosphere. 152 (2016) 431-438.

[27]. R. Uddin et al., Awareness regarding the importance of calcium and vitamin D among the undergraduate pharmacy students in Bangladesh, BMC Res. Notes. 6 (2013) 134. 